\section{Deep sclerectomy augmented with mitomycin $\mathrm{C}$}

N Anand and C Atherley
Department of

Ophthalmology

Calderdale \& Huddersfield

NHS Trust Huddersfield

Royal Infirmary

Huddersfield, UK

Correspondence: N Anand Department of

Ophthalmology

Huddersfield Royal Infirmary Lindley

Huddersfield HD3 3EA, UK

Tel: + 441484342526 .

E-mail: nitin.anand@

lycos.co.uk

Received: 20 January 2003 Accepted: 15 November 2003

Published online: 4 March 2005

\begin{abstract}
Aims To investigate the comparative efficacy and safety of deep sclerectomy with and without intraoperative mitomycin C (MMC) application for lowering the intraocular pressure (IOP).

Methods A total of 71 eyes of 71 consecutive patients who had routine deep sclerectomy (DS), nonaugmented (DS-noMMC) or with mitomycin C (DS-MMC) augmentation $(0.2 \mathrm{mg} / \mathrm{ml}$ for $2 \mathrm{~min})$ and follow-up of 4 months or more were identified from an ongoing prospective database on glaucoma surgery. Indications for MMC use were the presence of risk factors for subconjunctival scarring and low target IOPs. MMC $0.2 \mathrm{mg} / \mathrm{ml}$ was applied in the sub-Tenons space for $2 \mathrm{~min}$. Results There were 19 eyes in the DSnoMMC group and 52 eyes in the DS-MMC group. In 11 eyes (15.5\%), the procedure was complicated by intraoperative perforation of the trabeculo-Descemet's window. Eyes in the DS-MMC group had significantly lower IOPs (MANOVA, $P=0.04$ ). Kaplan-Meier survival curve analysis showed that the probability of maintaining IOP below target IOP level, below $18 \mathrm{mmHg}$ and below $14 \mathrm{mmHg}$ at 1 year was 51,67 , and $35 \%$ for the DS-noMMC group and 80,86 , and $74 \%$ for the DS-MMC group. The survival rates of the DS-MMC group were not statistically significant $(P=0.06)$ when the success criterion was maintaining an IOP less than $18 \mathrm{mmHg}$ but were significant for the other criteria, namely IOP less than target levels $(P=0.03)$ and less than $14 \mathrm{mmHg}$ $(P=0.03)$. Nd:YAG goniopuncture to lower IOP to target levels was done more frequently in the DS-noMMC group (13 eyes, $81 \%$ ) than the DS-MMC group (20 eyes, $45 \%$ ) and this difference was significant $(P=0.03)$. The prevalence of avascular areas within filtration blebs and transconjunctival oozing of aqueous was significantly higher in the DS-MMC group $(P<0.01)$.
\end{abstract}

Conclusions The use of intraoperative MMC during deep sclerectomy has a significant effect on the postoperative IOP and increases the probability of achieving target IOPs. However, our current technique of MMC application is associated with a higher incidence of avascular blebs and transconjunctival oozing.

Eye (2005) 19, 442-450. doi:10.1038/sj.eye.6701403 Published online 4 March 2005

Keywords: aged; deep sclerectomy; fluorouracil; goniopuncture; mitomycin C; trabeculectomy; viscocanalostomy

\section{Introduction}

Nonpenetrating glaucoma surgery (NPGS) in its various forms had been suggested as a safer alternative to trabeculectomy. ${ }^{1-8}$ Controversy ${ }^{9-18}$ surrounds the efficacy of these procedures compared to trabeculectomy in lowering the intraocular pressure (IOP) to the low levels required to stabilise visual field deterioration in advanced glaucoma ${ }^{19}$ and normal-tension glaucoma. ${ }^{20,21}$

A recent randomised trial has shown that intraoperative mitomycin C (MMC) application during deep sclerectomy (DS) results in lower IOPs. ${ }^{22}$ The aim of this study was to investigate the comparative efficacy and safety of deep sclerectomy with (DS-MMC) and without (DS-noMMC) intraoperative mitomycin application for lowering the IOP.

\section{Methods}

This study is retrospective in design. Consecutive patients who had undergone DS were included in the study. The eye operated first was included in patients who had bilateral 
DS. Data collection was done prospectively, on Microsoft Access $^{\mathrm{TM}}$, as part of an ongoing audit on glaucoma surgery. Postoperative parameters including applanation tonometry and bleb characteristics were made by one observer (NA).

Most of the procedures were performed or closely supervised by one surgeon (NA) using a standardized technique. These procedures were outside the learning curve of the surgeon, having performed approximately 150 deep sclerectomies in the year prior to this study. MMC-augmentation was conducted in eyes which had risk factors for subconjunctival fibrosis ${ }^{17}$ or where a low target IOP level $(<14 \mathrm{mmHg})$ had been set.

The technique for DS was broadly similar to that described by Mermoud and Schnyder. ${ }^{23}$ The procedures were performed under local anaesthesia (sub-Tenon's block). After a 6/0 vicryl corneal traction suture was passed through the superior cornea, the eye was rotated downwards. A wide, posterior fornix-based conjunctival flap was dissected. Where indicated, 2-4 collagen sponges (Visitec ${ }^{\mathrm{TM}}$, UK) soaked in MMC $0.2 \mathrm{mg} / \mathrm{ml}$, were applied for $2 \mathrm{~min}$ in the subconjunctival space taking care to avoid the sponges touching the conjunctival flap edges (Figure 1). The sponges were about $2 \mathrm{~mm}^{2}$ in size after soaking in MMC and were squeezed dry before application. The superficial scleral flap, trapezoid in shape, and approximately one-third scleral thickness, $5 \mathrm{~mm}$ at the limbus and $3 \mathrm{~mm}$ at the apex was outlined with a diamond knife and dissected with a No. 11 blade on a Beaver Knife handle. The

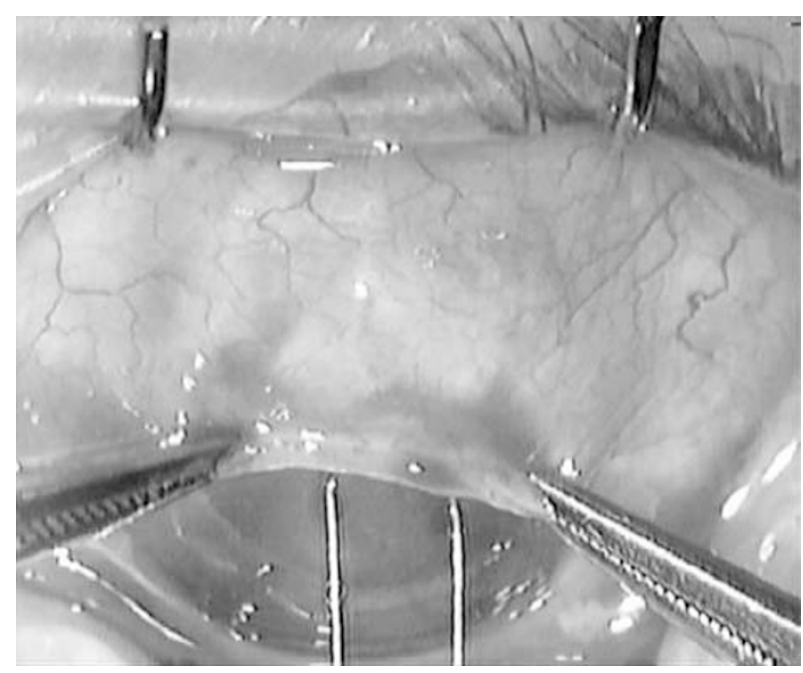

Figure 1 Technique for MMC application. Care was taken to avoid touch between the collagen sponges and the edge of the fornix-based conjunctival flap. dissection was carried 1-2 $\mathrm{mm}$ into clear cornea. The deep scleral flap was then delineated $1 \mathrm{~mm}$ within the edges of the superficial flap. The edges were deepened till the choroid was visible at the posteriorly and the Schlemm's canal was incised at the lateral edges. The deep flap was then dissected in the plane of the scleral spur, deroofing the Schlemm's canal and continued about $2 \mathrm{~mm}$ into clear cornea. The deep flap was then excised. Juxtacanalicular trabecular meshwork (JXT) was then peeled with a capsulorrhexis forceps. In later cases, $3.5 \mathrm{~mm}$ reticulated hyaluronic acid implant (SKGEL, Corneal) was then placed in the scleral bed as a spacer device and the superficial scleral flap sutured back loosely with two 10/0 nylon sutures. The conjunctiva was sutured onto clear cornea with two 10/0 nylon radial interrupted sutures.

Postoperatively, all patients received a topical steroid antibiotic combination for 6 weeks or more depending on bleb appearance. Subconjunctival betamethasone, $0.1 \mathrm{ml}$ $(0.4 \mathrm{mg})$ and 5-fluorouracil (5FU), $0.2 \mathrm{ml}(5 \mathrm{mg})$ were administered when signs of bleb failure were observed. Signs of bleb failure were as for trabeculectomy - disappearance of subconjunctival microcysts, increasing vascularity, decreasing area of the bleb, and increasing IOP on serial examination.

A careful slit-lamp examination under high magnification $(\times 16)$ for subconjunctival blebs was performed on each postoperative visit. An avascular area was defined as a conjunctival area within a bleb devoid of blood vessels and had either a transparent (cystic) or succulent appearance. Transconjunctival oozing (bleb sweating) and point leak were tested by asking the patient to look inferiorly, gently applying a dry sterile fluorescein strip on the avascular area and observation under cobalt blue slit-lamp illumination for at least 30 s. A point leak was manifested by a spontaneous visible flow of aqueous. Transconjunctival oozing was identified as increasing fluorescence on the bleb surface without any apparent interruption of the conjunctival tissue or aqueous stream on the bleb wall.

If target IOP levels were not achieved, Nd:YAG laser goniopuncture was performed. The laser treatment was performed using a LASAG 15 gonioscopy contact lens (CGA1, Haag Striet). Goniopunctures were performed using the free-running $\mathrm{Q}$-switched mode with an energy ranging from 2 to $4 \mathrm{~mJ}$ and 3-20 shots were applied. ${ }^{24}$ The trabeculo-Descemet's membrane (TDM) was seen as a semitransparent diaphanous membrane. The laser beam was aimed at the anterior edge of the TDM to avoid iris incarceration in the goniopuncture site. Needle revision on the slit-lamp bimicroscope with subconjunctival betamethasone $(0.04 \mathrm{mg})$ and $5 \mathrm{FU}(5 \mathrm{mg})$ was done 
mostly after Nd:YAG goniopuncture had failed to lower IOP to target levels.

\section{Statistical analysis}

Three criteria for success were used for Kaplan-Meier survival analysis - IOP below target level, below $18 \mathrm{mmHg}$, and below $14 \mathrm{mmHg}$. Comparison between the two groups was made by the log-rank test. Target IOP levels were set on an individual basis and depended on the age, extent of glaucomatous optic disc damage and field loss, and the findings of the Advanced Glaucoma Intervention Study (AGIS) ${ }^{19}$ and Collaborative NormalTension Glaucoma Study (CNTG). ${ }^{20}$ A Cox regression model was used to determine the effect of various factors on the survival curves. Dichotomous variables were analysed using the $\chi^{2}$ test with Yates correction and Fisher's exact test. Continuous variables (IOP) were analysed by analyses of variance (ANOVA) and between group comparisons by the Tukey HSD test.

Nonparametric data were analysed by the MannWhitney $U$-test. All tests were two-tailed and $P$-values less than 0.05 were taken to be significant.

\section{Results}

Patient demographics and preoperative characteristics are shown in Table 1 . There were 19 eyes in the DSnoMMC group and 52 eyes in the DS-MMC group. Detailed outcomes of the 11 eyes of 11 patients who either had perforations or were converted to trabeculectomy because of poor aqueous outflow are shown in Table 2.

Eyes in the DS-MMC group had significantly lower IOPs (MANOVA, $P=0.04$ ) and are shown in Figure 2.

Kaplan-Meier survival curve analysis showed that for all eyes (perforated and nonperforated), the probability of maintaining IOP below target IOP level, below $18 \mathrm{mmHg}$ and below $14 \mathrm{mmHg}$ at 1 year was 51,67 , and $35 \%$ for the DS-noMMC group and 80, 86, and 74\% for the DS-MMC group (Figures 3-5). The superior survival rates of the DS-MMC group were not statistically significant $(P=0.06)$ when the success criterion was maintaining an IOP less than $18 \mathrm{mmHg}$ but were significant for the other criteria, namely IOP less than target levels $(P=0.03)$ and less than $14 \mathrm{mmHg}(P=0.03)$. For eyes not complicated by intraoperative perforation, the probability of maintaining IOP below target level, below $18 \mathrm{mmHg}$ and below $14 \mathrm{mmHg}$ at 1 year by Kaplan-Meier survival curve analysis was 48,67 , and $28 \%$ for the DS-noMMC group and 88,90 , and $77 \%$ for the DS-MMC group. The differences between the groups with all three criteria were statistically significant by the log-rank test $(P<0.05)$. A Cox regression analysis model showed a
Table 1 Patient demographics and preoperative characteristics

\begin{tabular}{|c|c|c|c|}
\hline & $\begin{array}{l}\text { Non- } \\
\text { augmented } \\
\text { no. of eyes }\end{array}$ & $\begin{array}{c}\text { MMC- } \\
\text { augmented } \\
\text { no. of eyes }\end{array}$ & P-value \\
\hline No. of eyes and patients & 19 & 52 & \\
\hline Age (years) $(95 \% \mathrm{CI})$ & $\begin{array}{c}69.9 \\
(64.3-76.5)\end{array}$ & $\begin{array}{c}67.4 \\
(63.0-70.8)\end{array}$ & 0.48 \\
\hline \multicolumn{4}{|l|}{ Age (years) } \\
\hline$<50$ & $1(5.2 \%)$ & $5(9.6 \%)$ & \\
\hline$<40$ & $0(0 \%)$ & $3(5.8 \%)$ & \\
\hline Male/female & $9 / 10$ & $34 / 18$ & \\
\hline \multicolumn{4}{|l|}{ Race } \\
\hline Caucasian & $18(94.7 \%)$ & $47(90.4 \%)$ & \\
\hline Afro-Caribbean & $1(5.3 \%)$ & $3(5.8 \%)$ & \\
\hline Indian & $0(0 \%)$ & $2(3.8 \%)$ & \\
\hline \multicolumn{4}{|l|}{ Diagnosis } \\
\hline POAG & $16(100 \%)$ & $46(88.5 \%)$ & \\
\hline NTG & 0 & $4(7.7 \%)$ & \\
\hline Uveatic & 0 & $2(3.8 \%)$ & \\
\hline \multicolumn{4}{|l|}{ Coexisting ocular pathology } \\
\hline ARMD & 2 & 2 & \\
\hline CRVO & 0 & 1 & \\
\hline Cataract & 2 & 1 & \\
\hline Diabetic retinopathy & 0 & 1 & \\
\hline $\begin{array}{l}\text { Optic Disc cup:disc } \\
\text { ratio }>0.8\end{array}$ & $11(58 \%)$ & $37(71 \%)$ & 0.39 \\
\hline $\begin{array}{l}\text { Glaucomatous visual } \\
\text { field loss }\end{array}$ & $15(80 \%)$ & $48(92 \%)$ & 0.19 \\
\hline VF loss progression & $11(58 \%)$ & $38(73 \%)$ & 0.38 \\
\hline \multicolumn{4}{|l|}{ Previous laser } \\
\hline Peripheral Iridotomy & 0 & $4(7.7 \%)$ & \\
\hline Laser Trabeculoplasty & $1(5.3 \%)$ & $1(1.9 \%)$ & \\
\hline \multicolumn{4}{|l|}{ Previous surgery } \\
\hline Phacoemulsification & 0 & $2(3.8 \%)$ & \\
\hline ECCE & 0 & $3(5.8 \%)$ & \\
\hline $\begin{array}{l}\text { No. of glaucoma } \\
\text { medications } \\
\text { (range) }\end{array}$ & $2.0(1-5)$ & $2.3(1-5)$ & 0.42 \\
\hline
\end{tabular}

significant effect $(P=0.044)$ of MMC application on maintaining IOP below target level. Regression analysis showed no significant effect $(P>0.05)$ of age, sex, use of SKGEL Implant, preoperative IOP, IOP less than $6 \mathrm{mmHg}$ on the first postoperative day or laser goniopuncture (Table 3).

Goniopuncture to lower IOP to target levels was carried out in 13 eyes (81\%) of the DS-noMMC group and 20 eyes $(45 \%)$ of the DS-MMC group and this difference was significant $(P=0.03)$. Overall target IOPs were 
Table 2 DS complicated by intraoperative perforations or converted to trabeculectomy

\begin{tabular}{lccr}
\hline & Nonaugmented & $\begin{array}{c}\text { MMC- } \\
\text { augmented }\end{array}$ & Total \\
\hline No. of patients (eyes) & 2 & 9 & 11 \\
Perforation of TDM & 1 & 7 & 8 \\
Conversion to trabeculectomy & 1 & 2 & 3 \\
IOP & & & \\
$\quad<$ target & 2 & 7 & 9 \\
$\quad<18$ mmHg & 2 & 7 & 9 \\
$\quad<14$ mmHg & 2 & 7 & 9 \\
Hypotony (<5 mmHg) & 0 & 1 & 1 \\
Conjunctival bleb & & & \\
$\quad$ Avascular areas & & & 7 \\
$\quad$ Conjunctival oozing & 0 & 7 & 7 \\
$\quad$ Bleb-point leak & 0 & 1 & 1 \\
& 0 & & \\
Subsequent procedures & & 3 & 3 \\
$\quad$ Phacoemulsification & 0 & $1^{\mathrm{a}}$ & 1 \\
$\quad$ Revision of bleb + MMC & 0 & & 1 \\
$\quad$ Excision of avascular bleb & 0 & $1^{\mathrm{a}}$ & \\
\hline
\end{tabular}

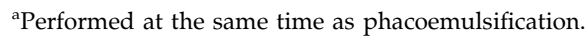

achieved in 24 of 33 eyes $(73 \%)$ by goniopuncture alone. Of the 20 patients, $16(80 \%)$ in the DS-MMC group achieved the target IOP after goniopuncture as compared to eight $(62 \%)$ in the DS-noMMC group and this was not significant $(P=0.42)$.
Except for perforations (11 cases, 15.5\%), there were few immediate complications related to the procedure (Table 4). One eye of the DS-MMC group had a persistent (2 months) lateral conjunctival edge-leak, which was successfully treated with cautery. A patient developed a delayed conjunctival edge-leak after sustaining minor trauma 4 months after surgery and underwent conjunctival resuturing. A point leak on an avascular cystic bleb was detected in a patient of the DS-MMC group 6 months after surgery. No case of ocular hypotony (IOP $<5 \mathrm{mmHg}$ ) was seen.

Four eyes had iris incarceration in the goniopuncture site with a consequent rise in IOP. All four eyes had shallow anterior chambers with a convex peripheral iris configuration. Three eyes were successfully treated by argon iridoplasty and one patient required surgical revision. Similarly, iris incarceration was noted in two eyes after needle revision (and prior goniopuncture) and these were treated with argon laser iridoplasty.

Postoperative manipulations and subsequent procedures are shown in Table 5.

No patient lost more than 2 Snellen chart lines of bestcorrected visual acuity (BCVA) in either group. The average change was 0.0 lines (range -2 to 3 )) in the DSnoMMC group and -0.18 lines (range -2 to 3 ) in the DSMMC group. This difference was not significant $(P=0.99)$. Two patients from each group are currently on medication to lower IOP.

Bleb characteristics are shown in Table 6. All patients had a detectable bleb on slit-lamp examination. Avascular

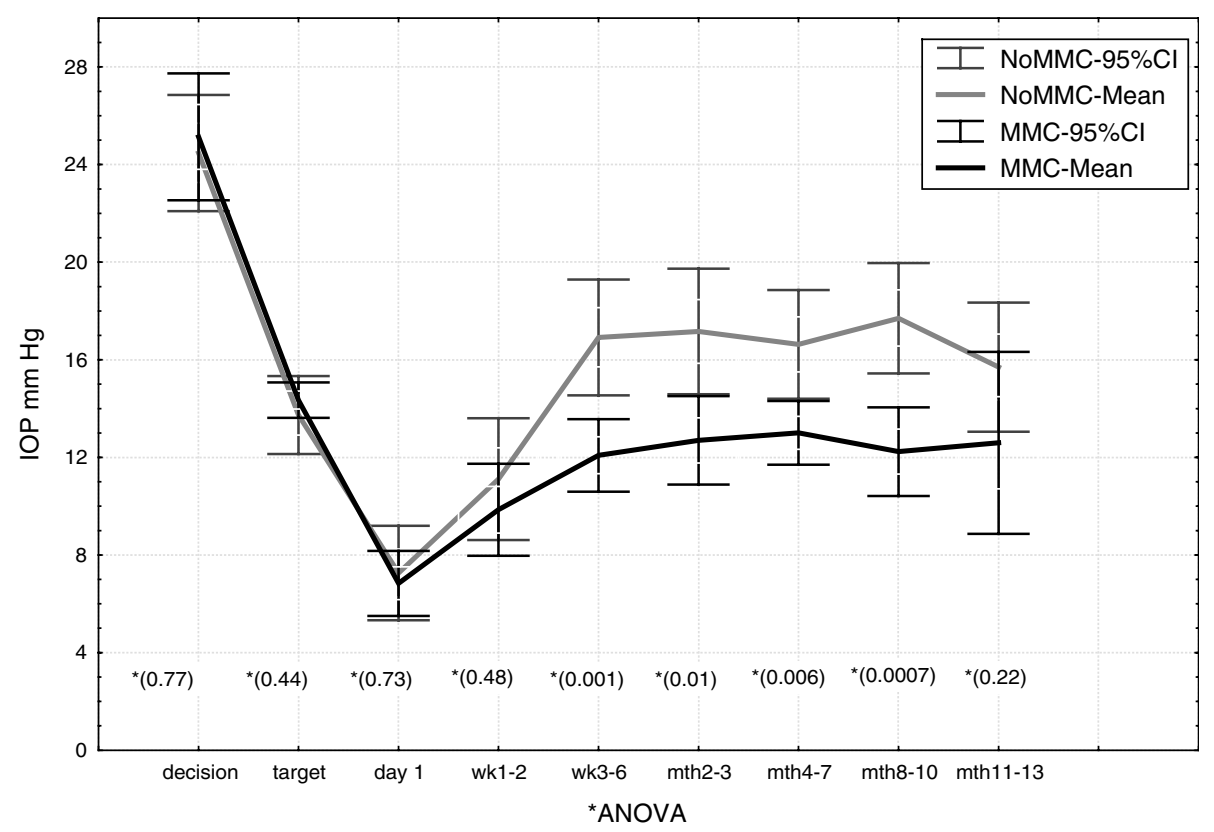

Figure 2 IOP changes after DS. IOP data were excluded after an eye underwent repeat glaucoma surgery. 


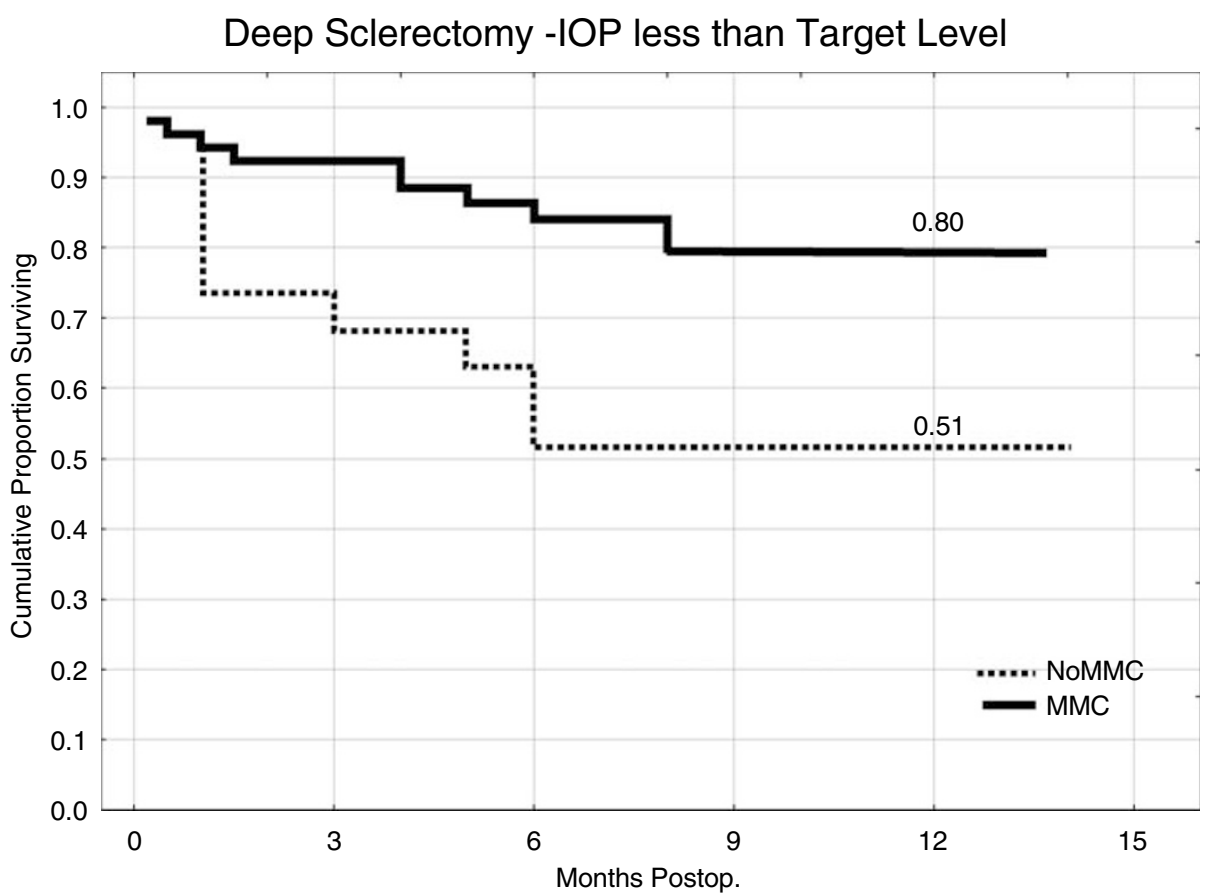

Figure 3 Kaplan-Meier survival curves with probability of maintaining IOP below target levels after DS (all eyes): log-rank test, $P=0.03$.

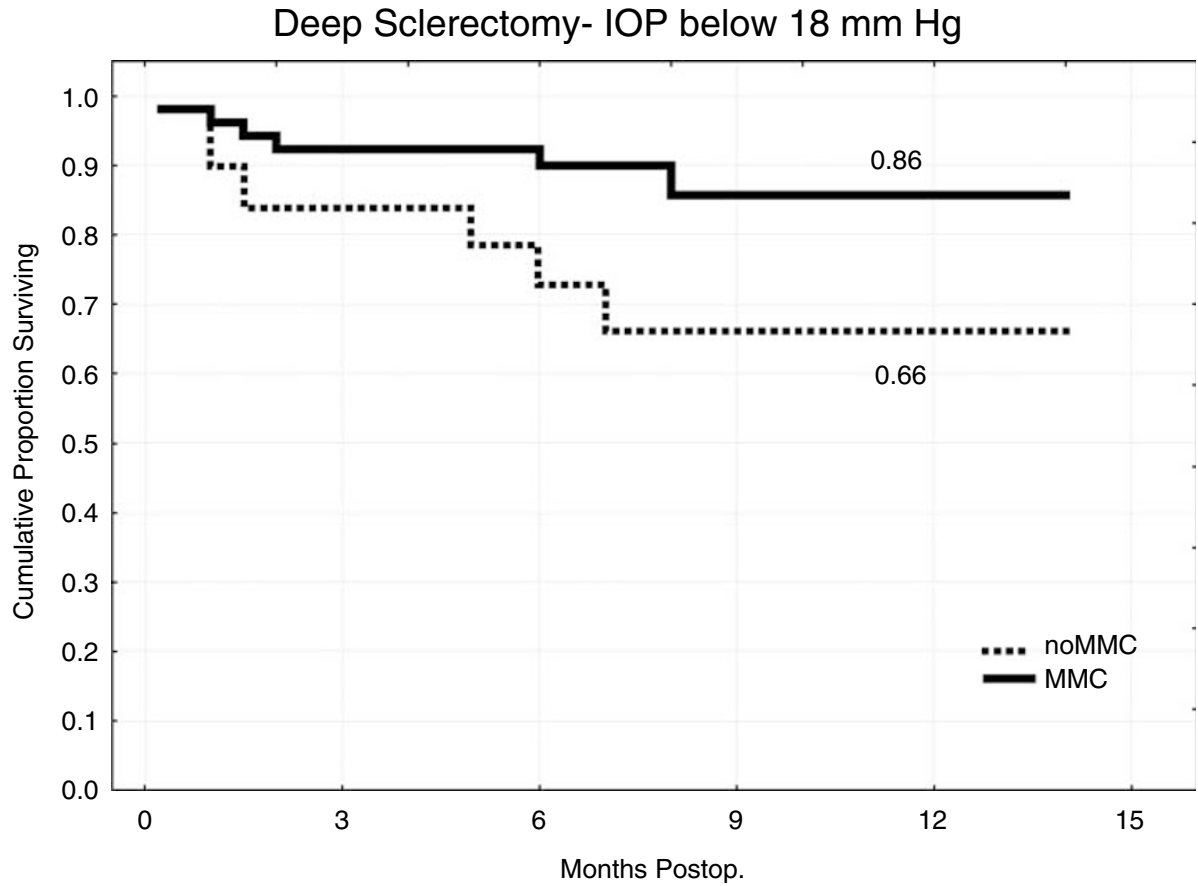

Figure 4 Kaplan-Meier survival curves with probability of maintaining IOP below $18 \mathrm{mmHg}$ after DS (all eyes): log-rank test, $P=0.06$

areas and trans-conjunctival oozing were seen more frequently in the DS-MMC group (Figure 5). Large diffuse blebs extending inferiorly were also seen more frequently in the DS-MMC group (Figure 6), although this was not statistically significant. Two patients, both from the DS-MMC group (nonperforated), with severe ocular discomfort due to large avascular blebs had compression sutures to limit the bleb to under the lid (Figure 7). 


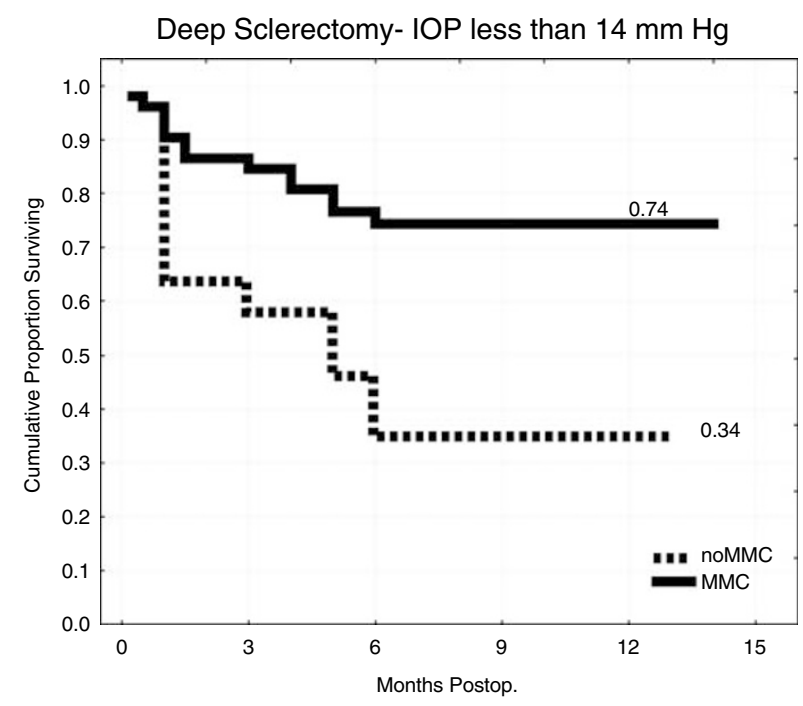

Figure 5 Kaplan-Meier survival curves with probability of maintaining IOP below $14 \mathrm{mmHg}$ after DS (all eyes): log-rank test, $P=0.03$.

Table 3 Cox regression analyses model for factors influencing probability of maintaining target IOP after uncomplicated DS

\begin{tabular}{lcc}
\hline & $\begin{array}{c}\text { Hazard ratio } \\
(95 \% \mathrm{CI})\end{array}$ & $\mathrm{P}$ \\
\hline Age & $1.02(0.97-1.06)$ & 0.40 \\
Sex & $1.68(0.5-5.66)$ & 0.44 \\
MMC application & $0.28(0.08-0.97)$ & $\mathbf{0 . 0 4}$ \\
SKGEL Implant & $1.04(0.22-4.99)$ & 0.96 \\
Nd:YAG goniopuncture & $1.67(0.43-6.33)$ & 0.45 \\
IOP $<6$ mmHg on day 1 postopcrative & $1.2(0.36-4.05)$ & 0.76 \\
IOP at decision to operate & $1.22(1.12-1.34)$ & 0.65
\end{tabular}

$\chi 2=8.30539, \mathrm{df}=7, P=0.3$.

Table 4 Complications of DS

\begin{tabular}{lccc}
\hline & $\begin{array}{c}\text { Nonaug- } \\
\text { mented } \\
\text { no. of eyes }\end{array}$ & $\begin{array}{c}\text { MMC- } \\
\text { augmented } \\
\text { no. of eyes }\end{array}$ & Total \\
\hline $\begin{array}{l}\text { Shallow AC } \\
\text { Transient conjunctival } \\
\text { wound-edge leak }\end{array}$ & $1(7.1 \%)$ & $5(11.4 \%)$ & $2(3.3 \%)$ \\
$\begin{array}{l}\text { Persistent conjunctival } \\
\text { wound-edge leak }\end{array}$ & 0 & $1(2.3 \%)$ & $1(1.6 \%)$ \\
$\begin{array}{l}\text { Conjunctival bleb } \\
\text { point leak }\end{array}$ & 0 & $1(2.3 \%)$ & $1(1.6 \%)$ \\
$\begin{array}{l}\text { Delayed conjunctival } \\
\text { edge-leak } \\
\text { (post traumatic) }\end{array}$ & 0 & $1(2.3 \%)$ & $1(1.6 \%)$ \\
$\begin{array}{l}\text { Microhyphaema } \\
\begin{array}{l}\text { Iris incarceration after } \\
\text { bleb needling }\end{array}\end{array}$ & $2(14.2 \%)$ & $1(2.3 \%)$ & $3(5 \%)$ \\
$\begin{array}{l}\text { Iris incarceration after } \\
\text { goniopuncture }\end{array}$ & $1(7.1 \%)$ & $2(4.5 \%)$ & $2(3.3 \%)$ \\
\hline
\end{tabular}

Table 5 DS not complicated by intraoperative perforation-subsequent procedures

\begin{tabular}{|c|c|c|c|}
\hline & $\begin{array}{l}\text { Nonaugmented } \\
\text { (no. of eyes) }\end{array}$ & $\begin{array}{c}\text { MMC- } \\
\text { augmented } \\
\text { (no. of eyes) }\end{array}$ & P-value \\
\hline Conjunctival cautery & $0(0 \%)$ & $1(2 \%)$ & $>0.05$ \\
\hline Conjunctival resuturing & $0(0 \%)$ & $1(2 \%)$ & $>0.05$ \\
\hline $\begin{array}{l}\text { Conjunctival compression } \\
\text { sutures }\end{array}$ & $0(0 \%)$ & $2(4 \%)$ & $>0.05$ \\
\hline Nd:YAG goniopuncture & $13(81 \%)$ & $20(45 \%)$ & 0.03 \\
\hline Argon iridoplasty & $1(6 \%)$ & $5(11 \%)$ & $>0.05$ \\
\hline $\begin{array}{l}\text { Subconjunctival 5-FU and } \\
\text { betamethasone }\end{array}$ & $9(56 \%)$ & $7(16 \%)$ & 0.004 \\
\hline Needle revision of bleb & $8(50 \%)$ & $2(5 \%)$ & 0.002 \\
\hline $\begin{array}{l}\text { Repeat trabeculectomy } \\
+\mathrm{MMC}\end{array}$ & $1(6 \%)$ & $0(0 \%)$ & $>0.05$ \\
\hline $\begin{array}{l}\text { Conversion to } \\
\text { trabeculectomy } \\
+\mathrm{MMC}\end{array}$ & $1(6 \%)$ & $1(2 \%)$ & $>0.05$ \\
\hline Phacoemulsification & $1(6 \%)$ & $0(0 \%)$ & $>0.05$ \\
\hline
\end{tabular}

Table 6 Conjunctival filtration bleb characteristics after uncomplicated DS

\begin{tabular}{lccc}
\hline & $\begin{array}{c}\text { Nonaug- } \\
\text { mented } \\
\text { (no. of eyes) }\end{array}$ & $\begin{array}{c}\text { MMC- } \\
\text { augmented } \\
\text { (no. of eyes) }\end{array}$ & P-value \\
\hline $\begin{array}{l}\text { Diffuse, inter-palpebral } \\
\text { blebs }\end{array}$ & $0(0 \%)$ & $7(16 \%)$ & 0.23 \\
$\begin{array}{l}\text { Cystic blebs } \\
\text { Encapsulated blebs }\end{array}$ & $3(18 \%)$ & $9(20 \%)$ & 1.0 \\
$\begin{array}{l}\text { Avascular areas in bleb } \\
\text { Trans-conjunctival oozing }\end{array}$ & $3(15 \%)$ & $0(0 \%)$ & 0.07 \\
\hline
\end{tabular}

\section{Discussion}

The study is retrospective in design. Data collection was, however, prospective as part of an ongoing audit of all glaucoma surgeries in our department. There was no randomisation and almost all patients with risk factors for failure and normal-tension glaucoma received MMC (Table 1). Despite this, success rates by all criteria were higher in the DS-MMC group, suggesting a significant beneficial IOP-lowering effect of MMC application during DS. We were unable to show that any other factor had any significant influence on the IOP outcomes (Table 3). The DS-MMC group had lower mean IOPs (by $6 \mathrm{mmHg}$ ) compared to the DS-noMMC group at all measured time-intervals after the third postoperative month. The power of the study, on retrospective calculation, to detect an IOP-difference of $6 \mathrm{mmHg}$ between the groups was very high (1.0).

Previous reports on NPGS have used an IOP less than $20-22 \mathrm{mmHg}$ as the criterion for success. ${ }^{2,3,5-8,13,15,17,18,22}$ 


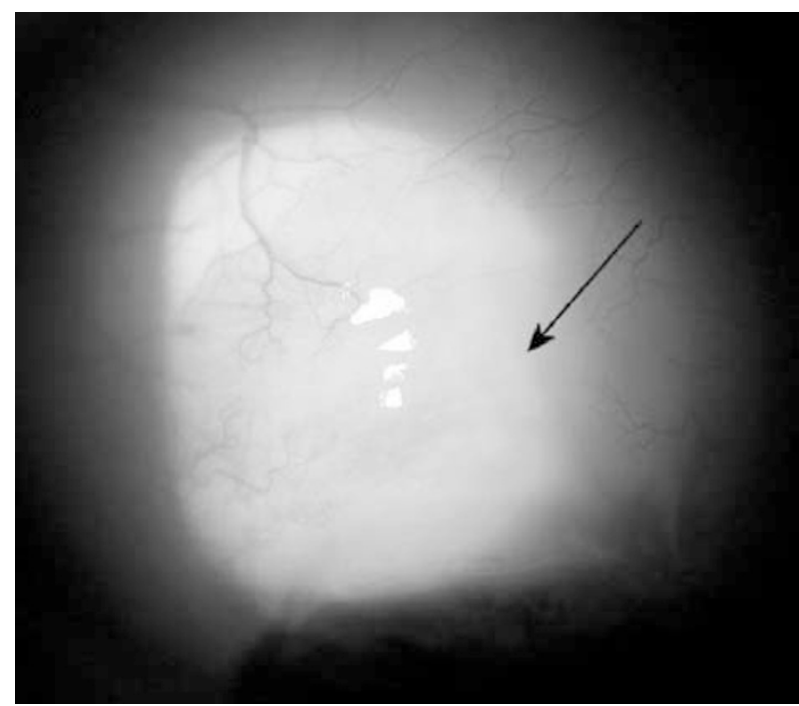

Figure 6 Typical filtration bleb 6 months after MMC-augmented DS. The underlying superficial scleral flap is just visible under avascular conjunctiva.

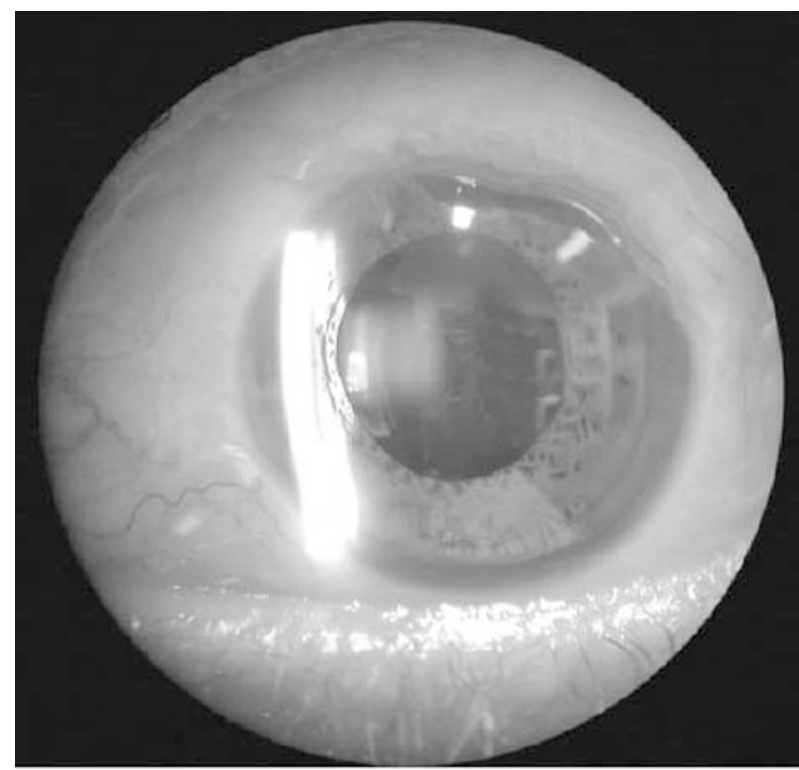

Figure 7 A circumferential bleb after MMC-augmented DS This patient benefited with delimiting compression sutures.

Criteria for success in this study were based on the results of the AGIS ${ }^{19}$ and NTG trials ${ }^{21}$ as $89 \%$ of the patients had advanced visual field loss and $69 \%$ had clear evidence of visual field progression (Table 1). The average target IOPs were quite low at $14.7 \pm 1.6$ (standard deviation) $\mathrm{mmHg}$ (Figure 1). The AGIS trial has demonstrated the importance of maintaining the IOP below $18 \mathrm{mmHg}$ in patients with established glaucomatous field loss. The group with the least chances of progression in this trial had an average IOP of $12.3 \mathrm{mmHg}$ over a period of 5 years. The NTG trial demonstrated a slower field loss progression if IOPs were reduced $30 \%$ from baseline. Setting lower target IOP levels has implications as evidenced by a high frequency of postoperative manipulations and laser goniopuncture in this study (Table 5).

The technique of MMC application in this study (subconjunctivally, $0.2 \mathrm{mg} / \mathrm{ml}$ for $2 \mathrm{~min}$, prior to scleral flap dissection) was similar to that described by Kozobolis $e t \mathrm{al}^{22}$ in their recent report $(0.2 \mathrm{mg} / \mathrm{ml}$ for $2.5 \mathrm{~min}) .^{22}$ This was the only report we could find after a detailed literature search using MEDLINE on MMC use with NPGS. The IOP in their study was decreased by $7.13 \mathrm{mmHg}$ or $27.59 \%$ in the nonenhanced DS group and by $11.68 \mathrm{mmHg}$ or $42.25 \%$ in the DS-MMC group at the end of the follow-up period and this difference was highly significant.

$\mathrm{O}^{\prime}$ Brart $e \mathrm{al}^{17}$ compared trabeculectomy augmented with 5-FU and MMC to non-augmented viscocanalostomy (VCT). ${ }^{17}$ Average IOPs at 6 and 12 months were approximately $14 \mathrm{mmHg}$ in the trabeculectomy with MMC group and $16 \mathrm{mmHg}$ in the VCT (with Healonid GV ${ }^{\mathrm{TM}}$ dilatation of Schlemm's canal) group. In comparison, in our study, the DS-MMC group had average IOPs consistently below $14 \mathrm{mmHg}$ and the DS-noMMC group had average IOPs between 16 and $18 \mathrm{mmHg}$ over the same period in the present study. This suggests that antimetabolite application would result in similar IOPs after both trabeculectomy and deep sclerectomy.

Mermoud et al reported a laser goniopuncture rate of $41 \%$ (52\% in this study) in their series of 100 DS procedures. Their immediate success rate was $83 \%$ and average drop in IOP was approximately $10 \mathrm{mmHg}$. Moreover, this drop was sustained for 2 years. ${ }^{24}$ Achieving target IOPs was the criteria for success in this study and our success rates were lower at $73 \%$. Further follow-up is needed to see if the IOP drops are maintained. Iris incarceration into the goniopuncture site in eyes with convex peripheral iris prompted us to modify the technique. We now use lower energy levels (usually $2-3 \mathrm{~mJ}$ ) and make a maximum of three noncontiguous punctures on the anterior edge of the TDM.

Most published trials comparing NPGS to trabeculectomy suggest a lower rate of complications including cataracts after NPGS. ${ }^{9,13,17,18}$ The AGIS trial estimated that the rate of cataract formation after the first trabeculectomy is $78 \%$ at 5 years. The risk of cataract is doubled if there is significant postoperative inflammation or a flat anterior chamber. ${ }^{25}$ These complications are rare after NPGS in experienced hands. ${ }^{5-7,12,26}$ Perforation of TDM during NPGS exposes 
the eye to the same risks as trabeculectomy but with increasing experience the incidence of perforations decreases significantly. ${ }^{6}$ It remains to be seen whether goniopuncture or MMC application increases the risks for cataract formation and late-onset endophthalmitis after NPGS. Shaarawy et $a l^{6}$ reported one case of blebitis and no case of endophthalmitis after follow-ups of 4 years or more after nonaugmented deep sclerectomy.

In this study, there was no statistically significant difference in IOP between the perforated and nonperforated DS. The average of all IOPs measured from 4 months onwards, after DS was $14.24 \pm 9.75 \mathrm{mmHg}$ (standard deviation) in eyes that had intraoperative perforation or were converted to trabeculectomy and $15 \pm 4.88 \mathrm{mmHg}$ in uncomplicated procedures. There was no difference in the IOPs at any interval between the uncomplicated and perforated eyes (MANOVA, $P=0.51$ ). The main complication of the procedure is accidental perforation of the TDM. One case of hypotony was observed after DS with MMC augmentation was converted to a trabeculectomy. There was a rapid progression of cataract in this eye. The hypotony resolved after phacoemulsification and excision of the avascular area of the bleb. To avoid a similar scenario, in MMC augmented deep sclerectomies, we now make the superficial scleral flap about half the thickness of the sclera. In case of perforation, the deep scleral flap is not excised and a standard trabeculectomy performed under the half-thickness flap with tight closure. Three eyes $(27 \%)$ in the perforated group and only one eye $(1.7 \%)$ in the nonperforated group had phacoemulsification during the follow-up period.

The mechanism of IOP lowering by NPGS remains a controversy. Multiple routes for aqueous drainage, including subconjunctival drainage, increased uveoscleral and transscleral filtration have been proposed. ${ }^{14,23}$ In a recent study on ultrasound biomicroscopy (UBM), a visible route under the scleral flap in and accidental perforation of the trabeculocorneal membrane was associated with long-term lowering of IOP. The presence of a 'subscleral aqueous lake' could not be equated to success, rather the presence of a communication between the subscleral space and the subconjunctival space. ${ }^{27}$ These findings are similar to those reported in a UBM study on trabeculectomy blebs. ${ }^{28}$ It has been proposed that dilatation of the Schlemm's canal induces breaks in the inner wall of the trabecular meshwork and removal of JXT creates microperforations. ${ }^{29}$ If subconjunctival drainage is the main pathway for aqueous outflow then, as in trabeculectomy, it is inevitable that the IOP would gradually increase with time due to progressive fibrosis at the episcleral-Tenons-subconjunctival interface. MMC application will decrease the fibrosis. There is also the additional possibility of progressive subscleral fibrosis and thickening of TDM causing failure.

Whatever the mechanism of action, the advantages of these procedures are self-evident. Minimal postoperative inflammation, ${ }^{30}$ deep anterior chambers, low risk of hypotony, and lower risk of cataract formation are some of the benefits. The use of MMC with DS increases the chances of achieving low IOPs while at the same time avoiding hypotony, not uncommon after MMCenhanced trabeculectomy. ${ }^{31}$ Further if the IOP starts increasing laser goniopuncture can be performed to lower IOP to target levels.

The prevalence of avascular areas within blebs was $70 \%$ and that of transconjunctival oozing was $48 \%$ in the DS-MMC group. The prevalence of avascular areas was less $(88 \%)$ and oozing $(11 \%)$ was higher than that following trabeculectomy with MMC reported by Matsuo et al. ${ }^{32}$ They had, however, used a lower concentration of MMC $(0.04 \mathrm{mg} / \mathrm{ml}$ compared to $0.2 \mathrm{mg} / \mathrm{ml}$ ). Their technique for examination was slightly different, using moistened fluorescein strips and observation for oozing for $15 \mathrm{~s}$. We used dry fluorescein strips and observed for a minimum of $30 \mathrm{~s}$. Most of their cases had longer follow-ups (3 months -4 years). It is possible that oozing may decrease with progressive fibrosis over time. Finally, they did not specify if these eyes had previous surgeries. Almost all our patients $(90 \%)$ had primary surgery. Perhaps applying MMC to a wider and posterior area with conjunctival clamps as suggested by Cordeiro et $a l^{33}$ and decreasing the concentration may decrease the prevalence of avascular blebs, point leaks, and oozing. We have changed our technique for MMC application and apply MMC more posteriorly and use a clamp to protect the edge of the fornix-based conjunctival flap.

The long-term consequences of thin avascular blebs after MMC-enhanced trabeculectomy include delayed bleb-leaks, cataract progression, hypotony with or without maculopathy, blebitis, and endophthalmitis. ${ }^{31,34}$ DeBry et $a l^{34}$ reported that the probability of a bleb leak, blebitis or endophthalmitis was $23 \%$ at 5 years after MMC- enhanced trabeculectomy. This may apply to blebs with similar characteristics after MMC-enhanced DSs especially in those eyes that have also undergone laser goniopuncture.

DS with MMC augmentation appears to be an effective surgical technique to decrease IOP to target levels, at least in the short term. Like in trabeculectomy, the high prevalence of avascular blebs and transconjunctival oozing after MMC-augmentation remains a cause for concern. 


\section{References}

1 Krasnov MM. Externalization of Schlemm's canal (sinusotomy) in glaucoma. Br J Ophthalmol 1968; 52. 157-161.

2 Zimmerman TJ, Kooner KS, Ford VJ, Olander KW, Mandlekorn RM, Rawlings EF et al. Trabeculectomy vs nonpenetrating trabeculectomy: a retrospective study of two procedures in phakic patients with glaucoma. Ophthalmic Surg 1984; 15: 734-740.

3 Zimmerman TJ, Kooner KS, Ford VJ, Olander KW, Mandlekorn RM, Rawlings FE et al. Effectiveness of nonpenetrating trabeculectomy in aphakic patients with glaucoma. Ophthalmic Surg 1984; 15: 44-50.

4 Hara T, Hara T. Deep sclerectomy with trabeculotomy $a b$ externo: one-stage procedure (DS 1). Ophthalmic Surg 1989; 20: 406-409.

5 Stegmann R, Pienaar A, Miller D. Viscocanalostomy for open-angle glaucoma in black African patients. J Cataract Refract Surg 1999; 25: 316-322.

6 Shaarawy T, Karlen M, Schnyder C, Achache F, Sanchez E, Mermoud A. Five-year results of deep sclerectomy with collagen implant. J Cataract Refract Surg 2001; 27: 1770-1778.

7 Sunaric-Megevand G, Leuenberger PM. Results of viscocanalostomy for primary open-angle glaucoma. Am J Ophthalmol 2001; 132: 221-228.

8 Wishart MS, Shergill T, Porooshani H. Viscocanalostomy and phacoviscocanalostomy: long-term results. J Cataract Refract Surg 2002; 28: 745-751.

9 Ambresin A, Shaarawy T, Mermoud A. Deep sclerectomy with collagen implant in one eye compared with trabeculectomy in the other eye of the same patient. J Glaucoma 2002; 11: 214-220.

10 Carassa RG, Bettin P, Brancato R. Viscocanalostomy vs trabeculectomy. Ophthalmology 2002; 109: 410-411.

11 Chiselita D. Non-penetrating deep sclerectomy versus trabeculectomy in primary open-angle glaucoma surgery. Eye 2001; 15: 197-201.

12 El Sayyad F, Helal M, El Kholify H, Khalil M, El Maghraby A. Nonpenetrating deep sclerectomy versus trabeculectomy in bilateral primary open-angle glaucoma. Ophthalmology 2000; 107: 1671-1674.

13 Jonescu-Cuypers C, Jacobi P, Konen W, Krieglstein G. Primary viscocanalostomy versus trabeculectomy in white patients with open-angle glaucoma: a randomized clinical trial. Ophthalmology 2001; 108: 254-258.

14 Lachkar Y, Hamard P. Nonpenetrating filtering surgery. Curr Opin Ophthalmol 2002; 13: 110-115.

15 Mermoud A, Schnyder CC, Sickenberg M, Chiou AG, Hediguer SE, Faggioni R. Comparison of deep sclerectomy with collagen implant and trabeculectomy in open-angle glaucoma. J Cataract Refract Surg 1999; 25: 323-331.

16 Netland PA. Nonpenetrating glaucoma surgery. Ophthalmology 2001; 108: 416-421.

17 O'Brart DP, Rowlands E, Islam N, Noury AM. A randomised, prospective study comparing trabeculectomy augmented with antimetabolites with a viscocanalostomy technique for the management of open angle glaucoma uncontrolled by medical therapy. Br J Ophthalmol 2002; 86: 748-754.

18 Luke C, Dietlein TS, Jacobi PC, Konen W, Krieglstein GK. A prospective randomized trial of viscocanalostomy versus trabeculectomy in open-angle glaucoma: a 1-year follow-up study. J Glaucoma 2002; 11: 294-299.
19 The AGIS Investigators. The advanced glaucoma intervention study (AGIS): 7 . The relationship between control of intraocular pressure and visual field deterioration. Am J Ophthalmol 2000; 130: 429-440.

20 Collaborative Normal-Tension Glaucoma Study Group. The effectiveness of intraocular pressure reduction in the treatment of normal-tension glaucoma. Am J Ophthalmol 1998; 126: 498-505.

21 Collaborative Normal-Tension Glaucoma Study Group. Comparison of glaucomatous progression between untreated patients with normal-tension glaucoma and patients with therapeutically reduced intraocular pressures. Am J Ophthalmol 1998; 126: 487-497.

22 Kozobolis VP, Christodoulakis EV, Tzanakis N, Zacharopoulos I, Pallikaris IG. Primary deep sclerectomy versus primary deep sclerectomy with the use of mitomycin C in primary open-angle glaucoma. J Glaucoma 2002; 11: 287-293.

23 Mermoud A, Schnyder CC. Nonpenetrating filtering surgery in glaucoma. Curr Opin Ophthalmol 2000; 11: 151-157.

24 Mermoud A, Karlen ME, Schnyder CC, Sickenberg M, Chiou AG, Hediguer SE et al. Nd:YAG goniopuncture after deep sclerectomy with collagen implant. Ophthalmic Surg Lasers 1999; 30: 120-125.

25 The advanced glaucoma intervention study, 8: risk of cataract formation after trabeculectomy. Arch Ophthalmol 2001; 119: 1771-1779.

26 Sanchez E, Schnyder CC, Sickenberg M, Chiou AG, Hediguer SE, Mermoud A. Deep sclerectomy: results with and without collagen implant. Int Ophthalmol 1996; 20: 157-162.

27 Roters S, Luke C, Jonescu-Cuypers CP, Engels BF, Jacobi PC, Konen $\mathrm{W}$ et al. Ultrasound biomicroscopy and its value in predicting the long term outcome of viscocanalostomy. $\mathrm{Br} \mathrm{J}$ Ophthalmol 2002; 86: 997-1001.

28 Jinza K, Saika S, Kin K, Ohnishi Y. Relationship between formation of a filtering bleb and an intrascleral aqueous drainage route after trabeculectomy: evaluation using ultrasound biomicroscopy. Ophthalmic Res 2000; 32: 240-243.

29 Johnson DH, Johnson M. How does nonpenetrating glaucoma surgery work? Aqueous outflow resistance and glaucoma surgery. J Glaucoma 2001; 10: 55-67.

30 Chiou AG, Mermoud A, Jewelewicz DA. Post-operative inflammation following deep sclerectomy with collagen implant versus standard trabeculectomy. Graefes Arch Clin Exp Ophthalmol 1998; 236: 593-596.

31 Bindlish R, Condon GP, Schlosser JD, D'Antonio J, Lauer $\mathrm{KB}$, Lehrer R. Efficacy and safety of mitomycin-C in primary trabeculectomy: five-year follow-up. Ophthalmology 2002; 109: 1336-1341.

32 Matsuo H, Tomidokoro A, Suzuki Y, Shirato S, Araie M. Late-onset transconjunctival oozing and point leak of aqueous humor from filtering bleb after trabeculectomy. Am J Ophthalmol 2002; 133: 456-462.

33 Cordeiro MF, Constable PH, Alexander RA, Bhattacharya SS, Khaw PT. Effect of varying the mitomycin-C treatment area in glaucoma filtration surgery in the rabbit. Invest Ophthalmol.Vis Sci 1997; 38: 1639-1646.

34 DeBry PW, Perkins TW, Heatley G, Kaufman P, Brumback LC. Incidence of late-onset bleb-related complications following trabeculectomy with mitomycin. Arch Ophthalmol 2002; 120: 297-300. 